\title{
BLUSUKAN: \\ Menelisik Gaya Kepemimpinan Nizam al-Muluk
}

\author{
Syamruddin Nasution \\ Fakultas Ushuluddin UIN Sultan Syarif Kasim Pekanbaru \\ Jl. H. Soebrantas No. 155, Pekanbaru, 28293 \\ e-mail: syamruddinnst@gmail.com
}

\begin{abstract}
Abstrak: Dalam menjalankan roda pemerintahan, belakangan ini beberapa pemimpin terjun langsung ke masyarakat untuk memahami kebutuhan rakyat secara langsung, populer sebagai blusukan. Konsep Blusukan ternyata memiliki akar dalam sejarah Muslim, meskipun di Indonesia baru popular belakangan ini. Nizam al-Muluk (Bani Saljuk) memanfaatkan blusukan dalam kepemimpinannya. Tulisan ini membahas kepemimpinan blusukan Nizam al-Muluk dan relevansinya terhadap Indonesia kontemporer. Blusukan setidaknya memiliki beberapa keistimewaan: pemimpin mendapatkan informasi paling mendesak dilakukan dari tangan pertama; informasi yang akurat memungkinkan formulasi solusi yang tepat; terbinanya kedekatan psikologis antara pemimpin dan rakyat. Jelas sekali bahwa ketiga aspek tersebut sangat dibutuhkan dalam realitas kepemimpinan Indonesia saat ini.
\end{abstract}

\begin{abstract}
Blusukan: In Search of the Style of Nizam al-Mulk's Leadership. In running the government, many a leaderopt to practice what popularly known as blusukan, i.e. going to and meeting the lower section of the society in person in order to understand the real problems of the grass root society. Popular in Indonesian context only in recent times, blusukan -has in fact a deep root in Muslim Political history. The Great Nizam al-Mulk of Saljuk Dynasty practiced it as part of his leadership. This article discusses blusukan as practiced by Nizam al-Mulk and tries to see its relevance to contemporary Indonesian political leadership. Blusukan has some merits: it allows a leader to receive first-hand and right-from-the-spot knowledge; accurate information and knowledge help to formulate an accurate solution; and it facilitates a strong psychological tie between the leader and his subjects. Apparently these three aspects are of utmost important in the reality of contemporary Indonesian leadership.
\end{abstract}

Kata Kunci: blusukan, Nizam al-Muluk, Daulah Abbasiyah. 
Syamruddin Nst: Blusukan (Menelisik Gaya Kepemimpinan Nizam al-Muluk)

\section{Pendahuluan}

Dalam sejarah perjalanan umat manusia, selalu saja ada pemimpin yang memiliki kelebihan apabila dibandingkan dengan pemimpin pada umumnya. Misalnya ada pemimpin yang dicintai rakyat karena mempunyai kebijakan yang pro rakyat. Di antara pemimpin yang sangat popular dan disenangi rakyat adalah Umar bin Khattab, khalifah rasyidah yang kedua. Mahatma Gandhi dari India demikian popular dan dikenang sepanjang masa karena dinilai hidup sederhana dan mementingkan rakyat. Nelson Mandela membuat orang acung jempol di antaranya karena politik amnestinya, yakni memaafkan penguasa sebelumnya, meskipun sang penguasa pernah memenjarakannya. Demikian seterusnya dengan Hugo Chavez, presiden Venezuela, dan Jens Stoltenberh, Perdana Menteri rakyat Norwegia, untuk mencatat sebagian di antara pemimpin yang sangat dicintai rakyat.

Pemimpin yang memiliki kelebihan dan dicintai rakyat di tingkat lokal Indonesia di antaranya kita mengenal mantan wali kota Solo, Joko Widodo (Jokowi) dan sekarang menjabat gubernur DKI Jakarta. Demikian juga wali kota Surabaya, Tri Rismaharini. Bahkan Tri Rismaharini akhir-akhir ini mendapat sorotan publik luar biasa karena prestasinya yang luar biasa. ${ }^{1}$ Dia terkenal sangat mementingkan persoalan dan kebutuhan rakyat, sementara para elite DPRD Surabaya kurang mendukungnya, bahkan boleh disebut menentangnya. Belakangan sikap DPRD memang sudah berubah karena menyadari dukungan yang luar biasa dari masyarakat Indonesia terhadap sang wali kota. ${ }^{2}$

Sejalan dengan itu, cara yang digunakan para pemimpin luar biasa ini, untuk memahami penderitaan dan kebutuhan rakyat, juga berbeda dengan cara yang digunakan pemimpin pada umumnya. Para pemimpin yang masih jarang ini berusaha memahami persoalan dan kebutuhan rakyat dengan langsung ke sumber masalah, rakyat. Cara langsung ini sekarang popular dengan sebutan blusukan. ${ }^{3}$ Dengan blusukan Umar ibn Khattab mengetahui ternyata ada umat kelaparan, yang oleh orang tuanya pura-pura sedanag memasak makanan untuk menenangkan jiwa anak yang sedang menangis karena kelaparan. Namun ketenangan psikis ada batasnya kalau perut masih lapar, maka si anak pun tidak dapat menahan tangisnya. Ketika itulah Umar lewat. Jokowi dalam blusukannya selalu membawa sembako, persediaan kalau ada rakyat yang memang betul-betul mem-

${ }^{1}$ Ada minimal 10 prestasi yang berkelas Asia-Fasifik dicapai oleh Kota Surabaya di bawah kepemimpinan walikota Tri Rismaharani.

${ }^{2}$ Fenomena yang menimpa Risma ini dapat dibaca salah satunya dalam laporan utama Tempo 17-23 Februari 2014, hlm. 34-47. Di antara tulisan yang muncul dalam laporan tersebut adalah tulisan 'Save Risma'. Konon tulisan ini juga dipampang masyarakat Surabaya di sejumlah kota, meskipun sang wali kota melarang dan memintanya agar diturunkan.

${ }^{3}$ Blusukan secara sederhana diartikan tindakan masuk dan keluar ke tempat yang jarang dimasuki orang. Tetapi dalam praktiknya, pemimpin blusukan dapat diartikan pemimpin yang turun langsung ke lapangan melihat kondisi yang sebenarnya dan berkomunikasi langsung dengan rakyat. Tujuan dari blusukan adalah untuk mengetahui masalah riil di lapangan. Dengan memahami persolan yang dihadapi masyarakat pastilah kebijakan dan program tepat sasaran dan tepat guna. 
butuhkan. Tri Rismaharini melakukan blusukan sejak paga jam 6 dan ajudan tidak pernah mengetahui ke mana arah blusukan. Substansi yang sama dengan bentuk berbeda dilakukan Jens Stoltenberh, Perdana Menteri Norwegia, dimana untuk mengetahui persoalan rakyat dilakukan dengan menyamar sebagai supir taksi. Dengan cara inilah sang pemimpin dapat mengetahui apa persoalan dan kesulitan rakyat, apa harapan rakyat dari sang pemimpin, dan bagaimana kesan rakyat terhadap kepemimpinannya.

Memang belum banyak gaya pemimpin blusukan, tetapi ke depan sepertinya tren ini akan semakin popular. Sebab dengan cara ini sang pemimpin dapat mengetahui dan merekam kebutuhan dan keinginan riil rakyat, yang dengan pengetahuan itu pula sang pemimpin dapat memenuhi dan menuntaskannya. Ini yang dirasakan rakyat Venezuela di era kepemimpinan Hugo Chavez, seorang pemimpin sosialis. Demikian juga rakyat Norwegia ketika pada masa kepemimpinan (Perdana Menteri) Jens Stoltenberh. Begitu rakyat mencintai Hugo Chavez, jalan-jalan di kota Venezuela dibanjiri pencintanya ketika memperingati setahun meninggalnya, Rabu 5 Maret 2014. Bersamaan dengan itu sejumlah demonstran juga membanjiri jalan-jalan untuk memprotes kepemimpinan Nikolas Maduro, suksesor Chavez yang dirasa mempunyai kebijakan yang tidak sejalan dengan pendahulunya, meskipun menurut pengakuan pendukung Nikolas, bahwa apa yang terjadi di Venezuela sekarang di era kepemimpinan Nikolas adalah 'perang psikologis' yang dibantu sejumlah Negara untuk mendukung oposisi. ${ }^{4}$ Sehingga pada hari yang sama, Rabu 5 Maret 2014, ada dua kelompok yang memenuhi jalan-jalan di kota Venezuela; satu kelompok pendukung dan pecinta Huga Chavez, sementara satu kelompok lagi ada pendukung oposisi yang mencari kesempatan di balik kekurangan Nikolas Maduro. Sehingga ke depan pemimpin yang menawarkan gaya kepemimpian blusukan ini yang berkenan dan dipilih rakyat, sebaliknya akan ditinggal gaya pemimpin 'menara gading'.

Dalam sejarah muslim ternyata bukan saja 'Umar bin Khattab yang mempunyai kebiasaan blusukan, Nizam al-Muluk (wazir Dinasti Saljuk) pun memanfaatkan blusukan dalam gaya kepemimpinannya. Menurut fakta sejarah ada minimal dua hal yang sangat penting diketahuai dari gaya kempimpinan Nizam al-Muluk, dan cocok digunakan untuk memimpin bangsa Indonesia ini sekarang, yakni: kebiasaan blusukan dan perhatiannya yang luar biasa terhadap perkembangan ilmu pengetahuan. Tindakannya yang langsung ke lapangan untuk mengetahui persoalan riil dan terlaksana atau tidaknya program yang dicanangkan ternyata membuahkan hasil yang luar biasa, dimana salah satu programnya yang sampai sekarang dirasakan buahnya adalah ketekunannya menangani pendidikan. Menurut catatan sejarah di masa kepemimpinan Nizam al-Muluk inilah pertama kali dibangun perguruan tinggi (pendidikan tinggi) yang ketika itu disebut madrasah.

4"Setahun Kepergian Hugo Chavez: Pemerintah Venazuela tuduh Perang Psikologi", dalam Kompas, Kamis, 6 Maret 2014, h. 9; "Venezuela Kenang Chavez: Maduro Putuskan Hubungan dengan Panama", dalam Kompas, Jumat 7 Maret 2014, h. 11. Panama dicatat salah satu Negara di balik munculnya demonstran yang menentang pemerintah Nikolas Maduro, sehingga pemerintah Venezuela memutuskan hubungan diplomatik dengan Panama. 
Kajian ini menjawab empat pokok masalah. Pertama, bagaimana bentuk karakter kepemimpinan blusukan Nizam al-Muluk. Kedua, bagaimana jurus yang digunakan Nizam al-Muluk untuk mengembalikan kejayaan Daulah Abbasiyah yang sudah diambang pintu kehancuran. Ketiga, bagaimana Nizam al-Muluk dapat memulai dan mengembangkan lembaga pendidikan tinggi. Keempat, apa relevansi mempelajari dan mengetahui kejayaan Nizam al-Muluk terhadap kehidupan kita sekarang di Indonesia dengan melakukan kontekstualisasi. Sebab kontekstualisasi inilah yang menjadi tujuan kita mempelajari dan mengetahui kejadian masa silam (sejarah), baik peristiwa maupun pemikiran. ${ }^{5}$ Namun empat pokok masalah ini dapat disederhanakan menjadi tiga, dengan menggabungkan pokok masalah kedua dan ketiga, dan ini yang disebutkan di abstrak dan kesimpulan.

Pada prinsipnya sumber data penelitian adalah sumber pustaka, dengan langkah pengumpulan data dimulai dari koleksi/akumulasi data, verifikasi data, interpretasi data, dan penulisan. ${ }^{6}$ Adapun sistematika bahasan tulisan ini setelah pendahuluan dibahas siapa Nizam al-Muluk, pemimpin blusukan yang cemerlang itu, dengan judul latar belakang kehidupan Nizam al-Muluk. Bahasan kemudian dilanjutkan dengan kupasan kebijakan apa yang ditempuh sang pemimpin luar biasa, yang di dalamnya dibahas (1) jurus yang digunakan Nizam al-Muluk untuk mengembalikan kejayaan Daulah Abbasiyah yang sudah diambang pintu kehancuran, (2) bagaimana Nizam al-Muluk dapat memulai dan mengembangkan lembaga pendidikan tinggi, dan (3) apa relevansi mempelajari dan mengetahui kejayaan Nizam al-Muluk terhadap kehidupan kita sekarang di Indonesia dengan melakukan kontekstualisasi. Akhirnya tulisan dipungkasi dengan catatan kesimpulan.

\section{Latar Belakang Kehidupan Nizam al-Muluk}

Nizam al-Muluk dilahirkan di Radkan, Tûs, Khurasan pada 10 April 1018 M. Nama aslinya Abû 'Alî al-Hasan ibn 'Alî ibn Ishâq al-Tûsi. Dia pindah ke Nisabur dan menuntut ilmu pada ulama mazhab al-Syâfi'î bernama Habbatullah al-Muwaffaq. Ayahnya adalah seorang pegawai pemerintah Gaznawi di Tûs, Khurasan. Ketika sebagian besar Khurasan jatuh ke tangan pasukan Bani Saljuk, ayahnya membawa Nizam al-Muluk pindah ke

${ }^{5}$ Tiga masalah penelitian ini pada prinsipnya telah mencakup lima objek yang sudah umum dalam kajian sejarah, yakni objek penelitian, peristiwa (what), orang yang melaksanakan (who), tempat kejadian (where), masa kejadian (when), dan mengapa kajadian terjadi (why). Taufik Abdullah, Sejarah dan Masyarakat (Jakarta: Pustaka Firdaus, 1987), h. 105. Dari sisi subjek penelitian masuk penelitian sejarah sosial (pendidikan), sebab subjek penelitian sejarah adalah politik, sosial, ekonomi dan gejala alam. Dudung Abdurrahman, Metode Penelitian Sejarah (Jakarta: Logos Wacana Ilmu, 1999).

${ }^{6}$ Badri Yatim, Historiografi Islam (Jakarta: Logos, 1997), h. 4. Oleh Kuntowijoyo disebut (1) tahap heuristic, (2) tahap kritik atau verifikasi, (3) tahap interpretasi atau aufessung, (4) tahap historiografi atau darstellung. Kuntowijoyo, Metodologi Sejarah (Yogyakarta: Tiara Wacana, 1994), h. 98. 
Khusrawjird dan kemudian pindah lagi ke Gazna. Di Gazna Nizam al-Muluk bekerja di kantor pemerintah Mahmud Gaznawi. ${ }^{7}$

Namun sekitar tiga atau empat tahun kemudian ia meninggalkan Gazna menuju ke daerah kekuasaan Bani Saljuk (1040/1041 M) di Balkh dan bekerja di sana, dan kemudian ia pindah lagi ke Marw. Kariernya meningkat lebih cepat sehingga dari sini ia ditarik oleh Sultan Saljuk, Alp Arselan, ke istananya di Baghdad dan kemudian diangkat menjadi Perdana Menteri (wazir), menggantikan Abu Ali Ahmad ibn Syazan, yang meninggal dunia. ${ }^{8}$

Nizam al-Muluk adalah seorang ahli politik, pemimpin militer yang bijaksana dan seorang filosof yang alim serta luas ilmu pengetahuannya. Dia terkenal pula sebagai seorang penulis berkebangsaan Persia yang ternama pada masanya. Dia menulis buku Siyasah Namah yang menjelaskan cara-cara menjalankan hal ikhwal wilayah-wilayah yang bisa menjamin kejayaan pemerintahan dan kebaikan rakyat jelata. ${ }^{9}$ Juga dijelaskan bahwa Nizam alMuluk adalah seorang yang alim, agamawan, dermawan, adil, penyantun, suka mema'afkan orang yang bersalah, sederhana, suka kebaikan dan senang menjamu dan menghibur fakir miskin.

Seperti ditulis sebelumnya, dari nama asli Nizam al-Muluk tersebut dapat diketahui bahwa dia adalah keturunan Persia dari kota Tus, daerah Khurasan wilayah Persia. Meski demikian dia tunduk dan patuh kepada kekuasaan Bani Saljuk sebab Khurasan dan Gazna saat itu berada di bawah kekuasaan Bani Saljuk. Dimana Turki Saljuk pada mulanya berasal dari suku bangsa Guzz yang berimigrasi dari Turkistan dan menetap di daerah Transoksania. Para ahli sejarah membagi Turki Saljuk kepada lima cabang, yakni; 1) Saljuk Iran, 2) Saljuk Irak, 3) Saljuk Kirman, 4) Saljuk Asia Kecil dan 5) Saljuk Syiria. ${ }^{10}$

Adapun hubungan antara Nizam al-Muluk dengan Daulah Saljuk terjadi pada saat Sultan kedua dari Bani Saljuk, Sultan Alp Arselan melihat kecakapan Nizam al-Muluk. Sultan menariknya ke istana di Baghdad dan diberi jabatan perdana menteri. Dengan demikian Sultan Alp Arselan didampingi seorang perdana menteri berkebangsaan Persia yang sangat cakap dan masyhur sampai wafat Sultan Alp Arselan dan Sultan Maliksyah, anak Sultan Alp Arselan, selama 20 tahun.

Pemerintahan Turki Saljuk di bawah Alp Arselan dapat berjalan dengan baik berkat bantuan dan sokongan dari Nizam al-Muluk karena Nizam al-Muluk menemani Alp Arselan dalam banyak peperangan. Demikian juga Nizam al-Muluk menemani Maliksyah anak Alp Arselan melancarkan serangan dan peperangan ke pihak musuh dan berhasil

${ }^{7}$ Tim Penulis, Ensiklopedi Islam (Jakarta: PT Ichtiar Baru Van Hoeve, 2001), jilid V, h. 43. ${ }^{8}$ Ibid.

${ }^{9}$ Ahmad Syalabi, Târîkh al-Islâmiy wa al-Had\}arah al-Islâmîyah, Jilid III (Mesir: Maktabah al-Nahdah al-Misrîyah, 1974), h. 433.

${ }^{10}$ Tim Penulis, Ensiklopedi Islam, h. 261. 
menaklukkan daerah sasaran. Bahkan Nizam al-Muluk sendiri memimpin tentara prajurut melakukan pertempuran-pertempuran dan berakhir dengan kemenangan yang cemerlang. ${ }^{11}$

Peran Nizam al-Muluk dalam mengokohkan pemerintahan Turki Saljuk yang hampir dilanda perpecahan juga dapat dilihat ketika Alp Arselan wafat, anak-anaknya berebut untuk menduduki tahta kerajaan, saat itu Nizam al-Muluk memainkan peranannya sebagai peredam gejolak yang terjadi di antara mereka dan berhasil mendudukkan Maliksyah sebagai Sultan. ${ }^{12}$

Bukti lain untuk menunjukkan betapa besar pengaruh dan peran Nizam al-Muluk dalam pemerintahan Turki Saljuk dapat dilihat pada satu kasus yang menimpa cucunya, Nizam al-Muluk yang melakukan tindakan tidak senonoh yang menimbulkan kemarahan Sultan Maliksyah. Ketika Maliksyah mengirim utusan untuk menghukum cucu tersebut, Nizam al-Muluk mencegah dan berkata; "Sampaikan kepada Sultan apakah dia masih belum tahu apa yang aku lakukan untuk kerajaaan ini, mesti dia sadar bahwa kalau bukan karena hasil usahaku, pasti dia tidak ada di tempatnya sekarang dan tidak memakai mahkota yang dipakainya saat ini". ${ }^{13}$

Dari sejumlah fakta sejarah tersebut di atas dapat disimpulkan betapa besar peran yang dimainkan Nizam al-Muluk dalam mengokohkan dan memajukan pemerintahan Turki Saljuk di bawah pemerintahan Daulah Abbasiyah. Karena Turki Saljuk berada dalam posisi membantu Daulah Abbasiyah maka kemajuan yang dicapai Nizam al-Muluk lebih tepat dikatakan memajukan pemerintahan Daulah Abbasiyah yang sedang berada dalam masa kemunduran, bahkan di ambang kehancuran.

Ketika dalam perjalanan dari Isfahan ke Baghdad di suatu tempat bernama Sinha Nahawand, Nizam al-Muluk dibunuh oleh seorang pasukan Hasan ibn Sabbah yang bertujuan menghidupkan aliran Syi'ah Fatimiyah pada tanggal 10 Ramadhan 485 H /14 Oktober $1092 \mathrm{M}$ dalam usia 74 tahun. ${ }^{14}$

\section{Kebijakan Nizam al-Muluk dalam Memimpin}

Nuzam al-Muluk adalah di antara pemimpin yang tercatat sejarah Islam menggunakan cara blusukan dalam kepemimpinannya. Dengan cara seperti ini ternyata Nuzam alMuluk dapat mengembalikan kejayaan dinasti Abbasiyah yang hampir tenggelam dan bersamaan dengan itu dapat pula menjadikan dinasti Abbasiyah sebagai pusat ilmu pengetahuan. Namun karakter ini belum banyak diungkap para penulis. Ini terjadi barangkali

${ }^{11}$ Ahmad Syalabi, Sejarah dan Kebudayaan Islam (Jakara: Pustaka al-Husna Baru, 2003), jilid III, h. 282.

${ }^{12} \mathrm{Ibid}$.

${ }^{13}$ Ibid., h. 282-283.

${ }^{14}$ Tim Penulis, Ensiklopedi Islam, h. 44. 
karena teori blusukan ini belum menjadi isu menarik bagi para penulis. Akibatnya, seolaholah hanya Umar bin Khattab yang melakukan blusukan dalam memahami masalah dan kebutuhan rakyat. Terungkapnya karaker Umar ini pun hanya karena sedemikian menonjolnya dibandingkan dengan pemimpin-pemimpin lain. Belakang tindakan blusukan ini menjadi salah satu ciri kepemimpinan yang didambakan masyarakat. Pada bagian ini tulisan berusaha mengungkapkan karakter kepemimpinan Nizam al-Muluk, baik kaitannya dengan karakter blusukannya maupun dalam kaitannya dengan keberhasilannya membangun pusat ilmu pengetahuan. Dengan memahami fakta sejarah ini diharapkan dapat menjadi pelajaran bagi para pemimpin bangsa Indonesia dalam menyelesaikan berbagai problem bangsa, sebab salah satu tujuan mempelajari sejarah adalah agar peristiwa masa lalu dapat menjadi pelajaran dalam rangka menyelesaikan masalah sekarang dengan melakukan kontekstualisasi.

Dalam jabatannya sebagai perdana menteri, Nizam al-Muluk menunjukkan kecakapannya sebagai seorang negarawan yang terpercaya. Ia memberikan nasehat kepada Sultan pada tiga hal. Pertama, untuk menjamin stabilitas negara perlu memberikan lapangan pekerjaan kepada pengungsi-pengungsi Turki yang datang ke Persia (Iran) akibat kemenangan Dinasti Saljuk. Kedua, meningkatkan kekuatan tempur angkatan bersenjata Dinasti Saljuk agar dapat menumpas pemberontakan, tetapi dengan syarat pemberontak yang menyerah harus diampuni. Ketiga, agar Dinasti juga harus tetap mempertahankan penguasa-penguasa lokal, baik Sunni maupun Syi'ah, dengan menunjuk anggota keluarga Bani Saljuk sebagai gubernur-gubernurnya. ${ }^{15}$

Nizam al-Muluk juga dikenal sebagai pemimpin yang sangat memperhatikan pendidikan. Sejumlah perguruan tinggi, ketika itu disebut madrasah, ada yang menyebut untuk zaman sekarang akademi ${ }^{16}$ ada juga yang menyebut universitas, ${ }^{17}$ didirikan di sejumlah kota. Madrasah paling terkenal yang didirikannya adalah Madrasah Nizamiyah di Baghdad yang diresmikan pada tahun $459 \mathrm{H} / 1067 \mathrm{M} .^{18}$

Madrasah Nizamiyah ini merupakan Perguruan Tinggi pertama yang menyediakan sarana belajar yang lebih memadai bagi para mahasiswa penuntut ilmu. Kemudian hampir setiap kota di Irak dan Iran (Khurasan) didirikan cabang-cabang dari Madrasah Nizamiyah tersebut. Di antara ulama yang mengajar di Madrasah Nizamiyah tersebut, selain al-

${ }^{15}$ Ibid., h. 43.

${ }^{16}$ A. L. Tibawi, "Origin and Character of al-Madrasah", Bulletin of the School of Oriental and African Studies, 25 (1962), h. 227, sebagaimana dikutip Hasan Asari, Menyingkap Zaman Keemasan Islam: Kajian atas Lembaga-lembaga Pendidikan (Bandung: Mizan, 1994), h. 44.

${ }^{17}$ Mehdi Nakosteen, History of Islamic Origins of Western Education, A.D. 800-1350 with an Introduction to Medieval Muslim Education (Boulder: The University of Colorado Press, 1964), h. 50, sebagaimana dikutip Hasan Asari, Menyingkap Zaman Keemasan Islam, h. 44.

${ }^{18}$ Sebuah studi menarik tentang Madrasah Nizamiyah dapat dibaca dalam Abd. Mukti. Konstruksi Pendidikan Islam: Belajar dari Kejayaan Madrasah Nizhamiyah Dinasti Saljuq (Bandung: Citapustaka Media, 2007). 
Juwaini dan al-Ghazali, adalah Syekh Abû Ishâq al-Syîrazi, Syekh Abû Nasr ibn al-Sabbaq dan Syekh Abû Mansur ibn Yûsuf ibn 'Abdul Malik. ${ }^{19}$

Pada mulanya Madrasah ini hanya ada di kota Baghdad, pusat pemerintahan Daulah Abbasiyah. Pada masa itu Madrasah tersebut tercatat sebagai tempat pendidikan paling masyhur. Kemudian Nizam al-Muluk mengembangkan madrasah tersebut dengan membuka di kota-kota yang berada di bawah kekuasaan Islam, baik di barat maupun di timur, seperti di Nisabur, Isfahan, Mousul, Bashrah dan Tibristan. Oleh karena itu pada mulanya kotakota tersebut adalah kota-kota yang tidak begitu dikenal tetapi berkembang dan berubah menjadi kota-kota terkenal sebagai pusat studi keilmuan di dunia Islam. Para pelajar berdatangan dari berbagai daerah ke kota-kota itu untuk mencari ilmu di madrasahmadrasah Nizamiyah tersebut.

Perhatian Nizam al-Muluk terhadap pengembangan sarana dan prasarana madrasah-madrasah adalah bagian dari kesungguhannya memperhatikan kemajuan pendidikan. Untuk meyakinkan programnya berjalan dengan baik dalam memajukan pendidikan, di samping memperbaiki sarana dan prasarana, dilakukan juga pembinaan. Dalam rangka pembinaan ini Nizam al-Muluk menyisihkan waktunya yang sangat sibuk untuk melakukan kunjungan secara bergiliran ke madrasah-madrasah Nizamiyah yang berada di berbagai kota tersebut. Bahkan disebutkan dalam kujungannya tersebut ia dengan penuh perhatian ikut menyimak dan mendengarkan kuliah-kuliah yang diberikan oleh guru di depan kelas dan terkadang ikut juga mengemukakan pikiran-pikirannya di depan para pelajar di madrasah-madrasah tersebut. ${ }^{20}$ Tindakan ini tentu sama dengan blusukan yang sekarang popular.

Berdasarkan pada karakter kepemimpinan Nizam al-Muluk, dapat ditulis dua catatan penting. Pertama, apa yang dilakukan Nizam al-Muluk ini kira-kira sama dengan blusukan yang sekarang dilakukan oleh sejumlah pemimpin masa kini, baik yang bersifat lokal maupun internasional. Di antara pemimpin lokal paling popular melakukan tindakan blusukan, sebagaimana disebutkan sebelumnya, adalah Joko Widodo (terkenal dengan sebutan Jokowi), mantan wali kota Solo, dan sekarang menjabat gubernur Daerah Khusus Ibu Kota Jakarta. Tindakan blusukan ini tentu bukan tujuan kepemimpinan, tetapi sarana untuk mengetahui (1) apa masalah rakyat, (2) apa kebutuhan rakyat, (3) apa yang diharapkan rakyat dari pemimpinnya, (4) apakah rencana kebijakan dan program sudah berjalan sebagaimana mestinya, dan (5) apakah kebijakan dan program yang sudah dilaksanakan dapat menyelesaikan masalah dan memenuhi kebutuhan rakyat.

Catatan penting kedua, kalau serius ingin melakukan sesuatu maka pemimpin harus betul-betul memberikan perhatian. Artinya ketika Nizam al-Muluk benar-benar memberikan perhatian terhadap pendidikan, maka terbukti dapat melahirkan generasi lahirnya lembaga

${ }^{19}$ Tim Penulis, Ensiklopedi Islam, h. 44.

${ }^{20}$ Ibid., h. 45. 
pendidikan ternama dan darinya juga lahir sejumlah ilmuwan. Sehingga kalau Indonesia benar-benar ingin memberantas korupsi, kolusi dan nepotisme, pemerintah harus memberikan perhatian serius, berkelanjutan, integratif, adil, dan tanpa mengenal lelah.

Demikian juga ketika kita ingin membangun karakter anak bangsa, maka pemerintah tidak boleh setengah-setengah. Sebagaimana diyakini sejumlah ahli bahwa salah satu cara yang dapat memotong praktek-praktek negatif dalam masyarakat adalah membangun karakter. Maka pemerintah harus serius, saling bahu-membahu dan saling mendukung dalam membangun karakter anak bangsa. Pimpinan harus memberikan perhatian serius dan berkelanjutan bagaimana agar karakter anak bangsa benar-benar dapat dibangun. Sebagaimana dipahami bahwa karakter atau kepribadian mempnyai tiga komponen, yakni; pengetahuan, sikap, dan perilaku, maka internalisasi karakter, bahwa terjadi internalisasi menjadi satu dari (1) pengetahuan, (2) sikap, (3) tingkahlaku. ${ }^{21}$

Akan lebih mujarab karakter positif dapat memotong penyakit anak bangsa, ketika karakter baik/mulia (good character) mencakup pengetahuan tentang kebaikan (moral knowing) yang menimbulkan komitmen terhadap kebaikan (moral feeling), dan akhirnya benar-benar melakukan kebaikan (moral behavior). ${ }^{22}$ Kalau generasi yang akan datang mempunyai karakter tersebut di atas, maka diharapkan dapat memutus penyakit-penyakit anak bangsa yang sekarang meradang. Sekedar contoh dari aplikas karakter baik, misalnya pemerintah melalui Kementerian Pendidikan dan Kebudayaan menetapkan lima karakter, sesuai dengan yang ditetapkan Kementerian Pendidikan Nasional tahun 2010. Karakter dimaksud ditetapkan lima nilai karakter inti:

1. Nilai-nilai perilaku manusia dalam hubungannya dengan Tuhan Yang Maha Esa.

2. Nilai-nilai perilaku manusian dalam hubungannya dengan diri sendiri.

3. Nilai-nilai perilaku manusia dalam hubungannya dengan sesama manusia.

4. Nilai-nilaiperilaku manusia dalam hubungannya dengan lingkungan.

5. Nilai-nilai perilaku manusia dalam hubungannya dengan kebangsaan.

Adapun butir-butir rincian dari masing-masing nilai tersebut adalah sebagai berikut:

\begin{tabular}{|l|l|l|}
\hline No & $\begin{array}{l}\text { Jangkauan Sikap dan } \\
\text { Perilaku }\end{array}$ & Butir-Butir Nilai Pendidikan Karakter \\
\hline 1 & $\begin{array}{l}\text { Nilai-nilai perilaku manusia } \\
\text { dalam hubungannya dengan } \\
\text { Tuhan Yang Maha Esa }\end{array}$ & Sifat religius \\
\hline
\end{tabular}

${ }^{21}$ Ahmad Tafsir, "Pengantar", dalam Abdul Majid, et al (ed.) Pendidikan Karakter dalam Perspektif Islam (Bandung: Rosdakarya, 2011), h. i.

${ }^{22}$ Marzuki, Prinsip Dasar Akhlak Mulia: Pengantar Studi Konsep-Konsep Dasar Etika dalam Islam (Yogyakarta: Debut Wahana Press-FISE UNY, 2011), h. 470. 


\begin{tabular}{|l|l|l|}
\hline 2 & $\begin{array}{l}\text { Nilai-nilai perilaku manusian } \\
\text { dalam hubungannya dengan } \\
\text { diri sendiri }\end{array}$ & $\begin{array}{l}\text { Jujur, bertanggung jawab, bergaya hidup sehat, } \\
\text { disiplin, kerja keras, percaya diri, berjiwa } \\
\text { wirausaha, berpikir logis, kreatif, kritis, } \\
\text { inovatif, mandiri, ingin tahun, cinta ilmu }\end{array}$ \\
\hline 3 & $\begin{array}{l}\text { Nilai-nilai perilaku manusia } \\
\text { dalam hubungannya dengan } \\
\text { sesama manusia }\end{array}$ & $\begin{array}{l}\text { Sadar hak dan kewajiban diri dan orang lain, } \\
\text { patuh pada aturan social, menghargai karya } \\
\text { dan prestasi orang lain, santun, demokratis }\end{array}$ \\
\hline 4 & $\begin{array}{l}\text { Nilai-nilaiperilaku manusia } \\
\text { dalam hubungannya dengan } \\
\text { lingkungan }\end{array}$ & Mencintai lingkungan dan alam sekitarnya \\
\hline 5 & $\begin{array}{l}\text { Nilai-nilai perilaku manusia } \\
\text { dalam hubungannya dengan } \\
\text { kebangsaan }\end{array}$ & Nasionalis, menghargai keberagaman \\
\hline
\end{tabular}

Dua catatan penting di atas merupakan hasil kontekstualisasi terhadap peristiwa yang terjadi dalam kehidupan Nizam al-Muluk. Sebab ada tiga tujuan dari kontekstualisasi terhadap peristiwa dan/atau pemikiran masa silam (sejarah). Pertama, untuk mencari relevansi. Kedua, untuk mencari hikmah untuk sekarang. Ketiga, untuk evaluasi target pencapaian. Tiga tujuan ini boleh dicapai sekaligus dari satu peristiwa, dan boleh juga hanya salah satu, atau dua dari tiga.

Dalam kajian terhadap kepemimpinan Nizam al-Muluk, dua catatan penting tersebut di atas boleh jadi sebagai konteks relevansi, tetapi tidak berlebihan kalau juga disebut hikmah di balik memahami riwayat hidup Nizam al-Muluk.

Dalam kaitannya dengan pembuktian teori sejarah, bahwa fakta sejarah dapat diuji kebenarannya dengan menggunakan tiga teori dalam sejarah, yakni: teori lingkaran, teori 'takdir', dan teori progres. ${ }^{23}$ Dengan mencermati fakta karakter kepemimpinan Nizam al-Muluk, yang kemudian dihubungkan dengan fakta yang terjadi sekarang, dapat disimpulkan bahwa apa yang terjadi di masa Nizam al-Muluk, juga terjadi sekarang. Dengan demikian, teori yang terbukti terjadi adalah pengulangan, yang berarti teori lingkaran, meskipun ada perbedaan bentuk.

Maksud dari penjelasan di atas, bahwa dengan menganalogkan dengan usaha Nizam al-Muluk dalam membangun bidang pendidikan ternyata dapat membuktikan bahwa di masa itulah lahirnya sejumlah perguruan tinggi Islam berkelas intenasional. Hasil dari pekerjaan itulah yang diwariskan dalam perkembangan dunia pendidikan masa-masa berikutnya.

Boleh dikatakan bahwa Lembaga Pendidikan Tinggi Islam pertama menerapkan

${ }^{23}$ Akh. Minhaji, Sejarah Sosial dalam Studi Islam: Teori, Metodologi dan Implementasi (Yogyakarta: SUKA Press, 2010), h. 104-106. 
sistem pendidikan klasikal adalah madrasah Nizamiyah. Hal itu dapat dilihat kelengkapan yang dimilikinya. Pertama, madrasah ini telah mempunyai kurikulum, dimana kurikulumnya berpusat pada al-Qur'an (membaca, menghafal dan menulis), sastra Arab, sejarah Nabi Muhammad Saw. dan berhitung. Kedua, tenaga pengajar mempunyai asisten, yang konon jumlahnya ada dua orang pelajar (mahasiswa) yang bertugas membaca dan menerangkan kembali kuliah yang telah diberikan oleh dosen kepada mahasiswa yang ketinggalan. Intinya, di masa ini sudah ada asisten dosen. Ketiga, madrasah ini telah menerapkan sistem pengajaran klasikal, dimana tenaga pengajar berdiri di depan kelas memberikan materi kuliah, sementara para mahasiswa duduk di kursi, yang kemudian dilanjutkan dengan dialog antara dosen dengan mahasiswa. ${ }^{24}$ Keempat, status tenaga pengajar (dosen) mendapat pengakuan dari Negara atau pemerintah. Mereka diangkat dan ditetapkan berdasarkan pengangkatan dari Khalifah dengan masa tugas tertentu seperti yang ada di zaman sekarang ini, sesuatu yang belum pernah diterapkan sebelumnya. Kelima, tenaga pengajar diberikan gaji tetap setiap bulan. Meskipun perlu dicatat bahwa kebijakan pemberian gaji bulanan ini ternyata belum sepenuhnya diterima tenaga pengajar. Mereka lebih suka tidak digaji tetapi kesejahteraan hidupnya terjamin. Mungkin saat itu menggaji guru dianggap langkah yang terlalu maju. ${ }^{25}$

Nama-nama besar yang mengabdikan diri untuk mengajar di madrasah nizamiyah antara lain adalah Syekh Abû Ishak al-Syîrazi; seorang fakih Baghdad, Syekh Abû Nasr ibn al-Sabbaq dan Syekh Abû Mansur ibn Yûsuf ibn Abdul Malik, Abû Qasim al-Alawi, al-Tibirizi, Imam al-Haramain al-Juwaini dan Imam al-Ghazali. ${ }^{26}$

Pada saat Imam al-Haramain al-Juwaini, salah seorang ulama besar aliran Asy'ari memimpin madrasah Nizamiyah di Nisabur, al-Ghazali datang ke Nisabur memasuki madrasah Nizamiyah tersebut berguru kepada al-Juwaini. Karena al-Juwaini melihat al-Ghazali berbakat dan berpotensi, maka diangkatnya menjadi asisten, yang kemudian dipercaya untuk menjadi penggantinya mengajar ketika gurunya berhalangan bahkan dipercaya mewakilinya sebagai pimpinan Nizamiyah. ${ }^{27}$

Setelah al-Juwaini (wafat 1085M) al-Ghazali meninggalkan Nisabur menuju Muaskar (Baghdad) atas undangan perdana menteri Nizam al-Muluk. Muaskar saat itu adalah tempat tinggal perdana menteri, para pembesar-pembesar kerajaan, para ulama/intelektual terkemuka. Melalui pertemuan-pertemuan ilmiah di istana Nizam al-Muluk menyebabkan nama Imam al-Ghazali semakin terkenal sehingga perdana menteri Nizam al-Muluk mengangkatnya menjadi guru besar (mudarris) pada madrasah Nizamiyah di Baghdad pada tahun 1090M. Ini merupakan kedudukan sangat terhormat dan prestasi puncak yang

\footnotetext{
${ }^{24}$ Tim Penulis, Ensiklopedi Islam, h. 45.

${ }^{25}$ Ibid.

${ }^{26} I b i d$.

${ }^{27}$ Tim Penulis, Ensiklopedi Islam, Jilid II (Jakarta: PT Ichtiar Baru Van Hoeve, 2001), h. 25.
} 
menyebabkan Imam al-Ghazali menjadi bagian dari kelompok elit kotaq Baghdad. Akan tetapi setelah lima tahun (1090-1095M) memangku jabatan tersebut, ia mengundurkan diri. $^{28}$

Dapat dicatat enam faktor yang menyebabkan Nizam al-Muluk berhasil dan mampu mengangkat kembali Daulah Abbasiyah yang sudah berada di ambang pintu kehancuran, dan mampu mengembangkan ilmu pengetahuan:

1. Sosok pribadi Nizam al-Muluk yang cekatan dan hebat; sebagai seorang ahli politik dan militer dia mampu mengendalikan Daulah Turki Saljuk dari perpecahan karena memperebutkan kekuasaan, sehingga tercipta pemerintahan yang stabil dalam pemerintahan Daulah Abbasiyah.

2. Nizam al-Mulk mampu menjalin kerja sama yang solid, baik dengan Turki Saljuk yang berdarah perang maupun dengan Daulah Abbasiyah yang menguasai Dunia Islam saat itu. Dengan kerja sama yang solid itu terbuka kesempatan mengembankan kemajuan peradaban Islam, khususnya bidang pendidikan.

3. Sebagai seorang ilmuan dan ulama besar, Nizam al-Muluk mampu memdirikan Universitas Nizamiyah di pusat pemerintahan kota Baghdad dan juga mendirikan sekolah-sekolah di pelbagai kota yang ada dalam wilayah pemerintahan Daulah Abbasiyah dengan melakukan inovasi-inovasi baru yang belum ada sebelumnya, di antaranya adalah status Universitas dan sekolah-sekolah yang secara resmi mendapat pengakuan dari pemerintahan Daulah Abbasiyah.

4. Para dosen dan guru yang mengajar di Universitas dan sekolah-sekolah tersebut mendapat pengakuan dan gaji tetap dari pemerintah, suatu hal yang belum pernah dilakukan pemerintah sebelumnya.

5. Mahasiswa tinggal di asrama dan biaya kuliah ditanggung negara, sehingga mahasiswa dapat belajar lebih konsentrasi. Demikian juga dengan sistem ini menarik minat para mahasiswa dari berbagai daerah untuk sekolah di Universitas dan sekolah-sekolah yang ada di kota-kota Nizamiyah.

6. Guru yang mengajar di sekolah-sekolah dan perguruan tinggi Nizamiyah terdiri dari ulama-ulama terkenal dan ternama, seperti Imam al-Haramain al-Juwaini dan Imam al-Ghazali.

\section{Penutup}

Dari bahasan di atas dapat dicatat tiga kesimpulan. Pertama, bentuk dan/atau karakter blusukan Nizam al-Muluk kira-kira sama dan dapat dilihat sebagai preseden dari blusukan yang dilakukan sejumlah pemimpin masa kini, baik yang bersifat lokal maupun inter-

${ }^{28}$ Ibid., h. 26. 
national. Fungsi dan/atau tujuan blusukan adalah sarana untuk mengetahui: (1) apa masalah rakyat, (2) apa kebutuhan rakyat, (3) apa yang diharapkan rakyat dari pemimpinnya, (4) apakah rencana kebijakan dan program sudah berjalan sesuai kebijakan dan program, dan (5) apakah kebijakan dan program yang sudah dilaksanakan dapat menyelesaikan masalah dan memenuhi kebutuhan rakyat.

Kedua, dapat dicatat enam faktor yang menyebabkan Nizam al-Muluk berhasil mengangkat kembali Daulah Abbasiyah yang sudah berada di ambang pintu kehancuran, dan mampu mengembangkan ilmu pengetahuan (1) sosok pribadi Nizam al-Muluk yang cekatan dan hebat; sebagai seorang ahli politik dan militer dia mampu mengendalikan Daulah Turki Saljuk dari perpecahan karena memperebutkan kekuasaan, sehingga tercipta pemerintahan yang stabil dalam pemerintahan Daulah Abbasiyah; (2) Nizam al-mulk mampu menjalin kerja sama yang solid, baik dengan Turki Saljuk maupun dengan Daulah Abbasiyah. Dengan kerja sama yang solid itu terbuka kesempatan mengembankan kemajuan peradaban Islam, khususnya bidang pendidikan (3) sebagai seorang ilmuan dan ulama besar, Nizam al-Muluk mampu mendirikan Madrasah Nizamiyah di pusat pemerintahan kota Baghdad dan di pelbagai kota lain dengan melakukan inovasi-inovasi tertentu; (4) para dosen yang mengajar di madrasah-madrasah tersebut mendapat pengakuan dan gaji tetap dari pemerintah, suatu hal yang belum pernah dilakukan pemerintah sebelumnya; (5) mahasiswa tinggal di asrama dan biaya kuliah ditanggung negara, sehingga mahasiswa dapat belajar lebih konsentrasi dan menarik mahasiswa dari berbagai daerah; dan (6) guru yang mengajar di madrasah-madrasah Nizamyah terdiri dari ulama-ulama terkenal dan ternama, seperti Imam al-Haramain al-Juwaini dan Imam al-Ghozali.

Ketiga, pelajaran yang dapat diambil dari karakter pemimpin blusukan bahwa model ini ada baiknya diteladani para pemimpin masa kini. Tujuannya adalah agar pemimpin dapat melaksanakana amanah rakyat dengan benar dan baik. Sebab blusukan ini terbukti dapat memuaskan rakyat karena dirasa dapat menyelesaikan masalah dan dapat memenuhi kebutuhan rakyat. Pelajaran kedua bahwa kalau serius ingin melakukan sesuatu maka pemimpin harus betul-betul memberikan perhatian. Kesungguhan Nizam al-Muluk memperhatikan pendidikan membuahkan lahirnya rangkaian lembaga pendidikan ternama yang kemudian melahirkan sejumlah ilmuwan dan ulama besar. Jika Indonesia benarbenar ingin menanamkan karakter baik kepada anak bangsa maka perhatian besar mesti diberikan kepada pendidikan melalui pola kepemimpinan yang benar-benar akrab dengan rakyat, termanifestasi antara lain melalui model blusukan.

\section{Pustaka Acuan}

Abd. Mukti. Konstruksi Pendidikan Islam: Belajar dari Kejayaan Madrasah Nizhamiyah Dinasti Saljuq. Bandung: Citapustaka Media, 2007.

Abdul Majid., et al. Pendidikan Karakter dalam Perspektif Islam. Bandung: Rosdakarya, 2011. 
Abdullah, Taufik. Sejarah dan Masyarakat. Jakarta: Pustaka Firdaus, 1987.

Abdurrahman, Dudung. Metode Penelitian Sejarah. Jakarta: Logos Wacana Ilmu, 1999.

Akh. Minhaji. Sejarah Sosial dalam Studi Islam: Teori, Metodologi dan Implementasi. Yogyakarta: Suka Press, 2010.

Asari, Hasan. Menyingkap Zaman Keemasan Islam: Kajian atas Lembaga-lembaga Pendidikan. Bandung: Mizan, 1994.

Kuntowijoyo. Metodologi Sejarah. Yogyakarta: Tiara Wacana, 1994.

Marzuki. Prinsip Dasar Akhlak Mulia: Pengantar Studi Konsep-Konsep Dasar Etika dalam Islam. Yogyakarta: Debut Wahana Press-FISE UNY, 2011.

"Setahun Kepergian Hugo Chavez: Pemerintah Venazuela Tuduh Perang Psikologi", dalam Kompas Kamis, 6 Maret 2014, h. 9;

Syalabi, Ahmad. Sejarah dan Kebudayaan Islam. Jakara: Pustaka al-Husna Baru, 2003), 4 jilid.

Syalabi, Ahmad. Târîkh al-Islâmiy wa al-Hadarah al-Islâmîyah. Mesir: Maktabah al-Nahdah al-Misrîyah, 1974, 4 vol.

Tempo, 17-23 Februari 2014, h. 34-47.

Tim Penulis. Ensiklopedi Islam. Jakarta: PT Ichtiar Baru Van Hoeve, 2001, 4 jilid.

"Venezuela Kenang Chavez: Maduro Putuskan Hubungan dengan Panama", dalam Kompas, Jumat 7 Maret 2014, h. 11.

Yatim, Badri. Historiografi Islam. Jakarta: Logos, 1997. 